\title{
CyberKnife enhanced conventionally fractionated chemoradiation for high grade glioma in close proximity to critical structures
}

\author{
Eric Oermann', Brian T Collins', Kelly T Erickson'1, Xia Yu1, Sue Lei1, Simeng Suy', Heather N Hanscom', Joy Kim', \\ Hyeon U Park', Andrew Eldabh1', Christopher Kalhorn², Kevin McGrail2, Deepa Subramaniam³, Walter C Jean ${ }^{1,2}$ and \\ Sean P Collins*1
}

\begin{abstract}
Introduction: With conventional radiation technique alone, it is difficult to deliver radical treatment ( $\geq 60 \mathrm{~Gy}$ ) to gliomas that are close to critical structures without incurring the risk of late radiation induced complications. Temozolomide-related improvements in high-grade glioma survival have placed a higher premium on optimal radiation therapy delivery. We investigated the safety and efficacy of utilizing highly conformal and precise Cyberknife radiotherapy to enhance conventional radiotherapy in the treatment of high grade glioma.

Methods: Between January 2002 and January 2009, 24 patients with good performance status and high-grade gliomas in close proximity to critical structures (i.e. eyes, optic nerves, optic chiasm and brainstem) were treated with the CyberKnife. All patients received conventional radiation therapy following tumor resection, with a median dose of 50 Gy (range: 40 - 50.4 Gy). Subsequently, an additional dose of 10 Gy was delivered in 5 successive 2 Gy daily fractions utilizing the CyberKnife image-guided radiosurgical system. The majority of patients (88\%) received concurrent and/or adjuvant Temozolmide.

Results: During CyberKnife treatments, the mean number of radiation beams utilized was 173 and the mean number of verification images was 58 . Among the 24 patients, the mean clinical treatment volume was $174 \mathrm{cc}$, the mean prescription isodose line was $73 \%$ and the mean percent target coverage was $94 \%$. At a median follow-up of 23 months for the glioblastoma multiforme cohort, the median survival was 18 months and the two-year survival rate was $37 \%$. At a median follow-up of 63 months for the anaplastic glioma cohort, the median survival has not been reached and the 4-year survival rate was $71 \%$. There have been no severe late complications referable to this radiation regimen in these patients.
\end{abstract}

Conclusion: We utilized fractionated CyberKnife radiotherapy as an adjunct to conventional radiation to improve the targeting accuracy of high-grade glioma radiation treatment. This technique was safe, effective and allowed for optimal dose-delivery in our patients. The value of image-guided radiation therapy for the treatment of high-grade gliomas deserves further study.

\section{Introduction}

High-grade gliomas are generally aggressive tumors with poor prognosis [1]. They tend to recur locally [2] and rarely spread beyond the confines of the central nervous system. Therefore, local control is considered the primary

* Correspondence: mbppkia@hotmail.com

1 Department of Radiation Oncology, Georgetown University Hospital, Washington, DC, USA

Full list of author information is available at the end of the article determinant of overall survival. Treatment routinely consists of maximum safe surgery followed by postoperative conventionally fractionated radiation therapy plus or minus chemotherapy [3-6]. With standard therapy, including Temozomide, the 2 year overall survival estimate for glioblastoma multiforme (GBM) is an improved but yet still disappointing 27\% [4]. Anaplastic glioma outcomes are considerably better with a 4 year overall survival estimate of approximately 50\% [5,6]. Current 
practice guidelines recommend treating high-grade gliomas with conventionally fractionated $(1.8-2.0 \mathrm{~Gy})$ partial brain irradiation over an approximately 6 week period [7]. The gross tumor volume (GTV) is targeted with large margins $(2-3 \mathrm{~cm})$ too addresses deep subclinical brain infiltration [8]. Radiosurgy with or without conventional irradiation is not recommended at this time given the poor tolerance of the normal brain to hypofractionation [9] and disappointing published treatment outcomes [10-13].

Presently, it is our clinical practice to treat high-grade glioma patients with maximum safe surgery followed by 6 weeks of chemoradiation (60 Gy partial brain irradiation in 2 Gy fractions with concurrent and adjuvant Temozolomide). It has been generally feasible with conventional radiation technique to deliver such "full dose" treatment while respecting institutional peritumoral critical structure maximum point dose tolerances (Table 1). However, for some deep seated tumors, typically involving the temporal and frontal lobes, such treatment is often not feasible with conventional treatment inaccuracies approaching $5 \mathrm{~mm}$ in the best hands $[14,15]$. Historically, the total radiation dose has been lowered in such cases to protect normal tissue function with the understanding that such treatment modifications could adversely affect overall survival [16]. With recent Temozolomide-related improvements in high-grade glioma survival [4], it is now more likely than ever that suboptimal radiation treatment will result in either a decrement in overall survival or an increase in late radiation toxicity.

The CyberKnife, a commercially available frameless image-guided radiosurgery system (Accuray, Sunnyvale, CA), was installed at Georgetown University Hospital in late 2001. Standard components include a light weight linear accelerator, a robotic manipulator and an automated $\mathrm{x}$-ray image-guided computer targeting system. Generally, the treatment planning system with input from

Table 1: Cumulative Radiation Maximum Point Dose Limits

\begin{tabular}{lc}
\hline Critical Structure & $\begin{array}{c}\text { Maximum Point Dose Limit (total for } \\
\mathbf{3 0} \text { fractions) }\end{array}$ \\
\hline Lens & $10 \mathrm{~Gy}$ \\
\hline Retina & $50 \mathrm{~Gy}$ \\
\hline Optic Nerve & $55 \mathrm{~Gy}$ \\
\hline Optic Chiasm & $55 \mathrm{~Gy}$ \\
\hline Brainstem & $55 \mathrm{~Gy}$ \\
\hline
\end{tabular}

the user selects hundreds of small non-isocentric circular radiation beams to deliver a highly conformal radiation treatment with steep dose gradients to a defined target in order to spare normal tissues $[17,18]$. Subsequently, the automated robotic manipulator directed by the frequently updated $\mathrm{x}$-ray targeting system's knowledge of the patient's unique cranial anatomy efficiently delivers the selected radiation beams with submilimeter accuracy. We report the safety and efficacy of using the highly conformal and accurate CyberKnife radiosurgery system to enhance the final week of conventional radiotherapy in 24 patients with high-grade gliomas in close proximity to critical structures.

\section{Patients and Methods Patient Population}

Patients with newly diagnosed resected unifocal highgrade gliomas (WHO Grade III and VI) in close proximity $(<1 \mathrm{~cm})$ to critical structures (Table 2$)$ were evaluated. All patients were in RPA class 1 to 4 [19,20]. Magnetic resonance imaging (MRI) was completed preoperatively and postoperatively. The Georgetown University Hospital institutional review board approved this study and all participants provided informed written consent.

\section{Surgery}

The extent of surgical resection was documented as total tumor resection or subtotal tumor resection following review of operative reports and post operative MRI imaging (Table 2). Salvage surgery was routinely recommended for patients with good performance status and evidence of recurrence or radiation necrosis based on imaging studies.

\section{Conventional Radiation Treatment}

Patients were placed in the supine treatment position with their heads resting on a standard support. A custom thermoplastic mask was crafted. Thin-sliced $(1.25 \mathrm{~mm})$ high-resolution $\mathrm{CT}$ images were obtained through the cranium for conventional and CyberKnife treatment planning. Treatment planning MRI imaging was completed selectively to enhance target and critical structure delineation when clinically indicated. Target volumes and critical structures were contoured by team neurosurgeons. Treatment volumes were generous including the contrast enhancing tumor volume when present and the surgical defect with a $3 \mathrm{~cm}$ margin. Critical structures in close proximity to the target volume were not excluded from the treatment volume during conventional radiation treatment. Forty to 50.4 Gy was delivered in 1.8 to 2.0 Gy fractions 5 days a week for a total of 4 to $51 / 2$ weeks. Treatment was delivered using linear accelerators with nominal energies $\geq 6 \mathrm{MV}$. Intensity modulated radiation therapy (IMRT) technique was not permitted. 
Table 2: Patient Characteristics

\begin{tabular}{|c|c|c|c|c|c|c|c|c|}
\hline Patient & Histology & Resection & Chemotherapy & Lobe & RPA & Age & Sex & Deficit \\
\hline 1 & $\begin{array}{l}\text { Glioblastoma } \\
\text { multiforme }\end{array}$ & Total & $\begin{array}{c}\text { Concurrent and } \\
\text { Adjuvant }\end{array}$ & Frontal-L & 4 & 60 & Male & No \\
\hline 2 & $\begin{array}{l}\text { Glioblastoma } \\
\text { multiforme }\end{array}$ & Subtotal & $\begin{array}{c}\text { Concurrent and } \\
\text { Adjuvant }\end{array}$ & Frontal-L & 3 & 44 & Female & No \\
\hline 3 & $\begin{array}{c}\text { Anaplastic } \\
\text { oligodendroglioma }\end{array}$ & Total & Adjuvant & Frontal-L & 1 & 27 & Male & No \\
\hline 4 & $\begin{array}{c}\text { Anaplastic } \\
\text { oligoastrocytoma }\end{array}$ & Total & None & Frontal-R & 1 & 33 & Male & No \\
\hline 5 & $\begin{array}{c}\text { Anaplastic } \\
\text { astrocytoma }\end{array}$ & Total & Adjuvant & Frontal-R & 1 & 42 & Female & No \\
\hline 6 & $\begin{array}{c}\text { Anaplastic } \\
\text { oligodendroglioma }\end{array}$ & Total & $\begin{array}{c}\text { Concurrent and } \\
\text { Adjuvant }\end{array}$ & Frontal-R & 1 & 42 & Male & No \\
\hline 7 & $\begin{array}{c}\text { Anaplastic } \\
\text { astrocytoma }\end{array}$ & Total & Adjuvant & Frontal-R & 1 & 39 & Female & No \\
\hline 8 & $\begin{array}{c}\text { Anaplastic } \\
\text { astrocytoma }\end{array}$ & Subtotal & $\begin{array}{c}\text { Concurrent and } \\
\text { Adjuvant }\end{array}$ & Frontal-R & 2 & 62 & Female & Yes \\
\hline 9 & $\begin{array}{l}\text { Glioblastoma } \\
\text { multiforme }\end{array}$ & Total & $\begin{array}{c}\text { Concurrent and } \\
\text { Adjuvant }\end{array}$ & Occipital-R & 4 & 70 & Female & No \\
\hline 10 & $\begin{array}{c}\text { Anaplastic } \\
\text { oligoastrocytoma }\end{array}$ & Total & Adjuvant & Parietal-R & 1 & 48 & Male & No \\
\hline 11 & $\begin{array}{c}\text { Anaplastic } \\
\text { oligoastrocytoma }\end{array}$ & Total & Adjuvant & Temporal-L & 1 & 42 & Male & No \\
\hline 12 & $\begin{array}{l}\text { Glioblastoma } \\
\text { multiforme }\end{array}$ & Total & $\begin{array}{c}\text { Concurrent and } \\
\text { Adjuvant }\end{array}$ & Temporal-L & 4 & 72 & Female & No \\
\hline 13 & $\begin{array}{c}\text { Anaplastic } \\
\text { astrocytoma }\end{array}$ & Subtotal & $\begin{array}{c}\text { Concurrent and } \\
\text { Adjuvant }\end{array}$ & Temporal-L & 1 & 28 & Female & No \\
\hline 14 & $\begin{array}{l}\text { Glioblastoma } \\
\text { multiforme }\end{array}$ & Subtotal & $\begin{array}{c}\text { Concurrent and } \\
\text { Adjuvant }\end{array}$ & Temporal-L & 4 & 51 & Female & No \\
\hline 15 & $\begin{array}{c}\text { Anaplastic } \\
\text { astrocytoma }\end{array}$ & Total & $\begin{array}{c}\text { Concurrent and } \\
\text { Adjuvant }\end{array}$ & Temporal-R & 2 & 66 & Female & No \\
\hline 16 & $\begin{array}{l}\text { Glioblastoma } \\
\text { multiforme }\end{array}$ & Subtotal & $\begin{array}{c}\text { Concurrent and } \\
\text { Adjuvant }\end{array}$ & Temporal-R & 4 & 63 & Female & No \\
\hline 17 & $\begin{array}{l}\text { Glioblastoma } \\
\text { multiforme }\end{array}$ & Subtotal & $\begin{array}{c}\text { Concurrent and } \\
\text { Adjuvant }\end{array}$ & Temporal-R & 4 & 59 & Female & No \\
\hline
\end{tabular}


Table 2: Patient Characteristics (Continued)

\begin{tabular}{|c|c|c|c|c|c|c|c|c|}
\hline 18 & $\begin{array}{l}\text { Glioblastoma } \\
\text { multiforme }\end{array}$ & Subtotal & $\begin{array}{c}\text { Concurrent and } \\
\text { Adjuvant }\end{array}$ & Temporal-R & 4 & 56 & Male & No \\
\hline 19 & $\begin{array}{c}\text { Anaplastic } \\
\text { astrocytoma }\end{array}$ & Subtotal & $\begin{array}{c}\text { Concurrent and } \\
\text { Adjuvant }\end{array}$ & Temporal-R & 2 & 67 & Male & No \\
\hline 20 & $\begin{array}{l}\text { Glioblastoma } \\
\text { multiforme }\end{array}$ & Total & $\begin{array}{c}\text { Concurrent and } \\
\text { Adjuvant }\end{array}$ & Temporal-R & 4 & 69 & Male & No \\
\hline 21 & $\begin{array}{c}\text { Anaplastic } \\
\text { astrocytoma }\end{array}$ & Total & $\begin{array}{c}\text { Concurrent and } \\
\text { Adjuvant }\end{array}$ & Temporal-R & 1 & 16 & Male & No \\
\hline 22 & $\begin{array}{l}\text { Glioblastoma } \\
\text { multiforme }\end{array}$ & Subtotal & $\begin{array}{c}\text { Concurrent and } \\
\text { Adjuvant }\end{array}$ & Temporal-R & 4 & 55 & Male & No \\
\hline 23 & $\begin{array}{l}\text { Glioblastoma } \\
\text { multiforme }\end{array}$ & Subtotal & $\begin{array}{c}\text { Concurrent and } \\
\text { Adjuvant }\end{array}$ & Temporal-R & 4 & 57 & Male & No \\
\hline 24 & $\begin{array}{l}\text { Glioblastoma } \\
\text { multiforme }\end{array}$ & Subtotal & $\begin{array}{c}\text { Concurrent and } \\
\text { Adjuvant }\end{array}$ & Temporal-R & 4 & 65 & Female & No \\
\hline
\end{tabular}

\section{CyberKnife Treatment}

Following the completion of conventional radiation therapy, CyberKnife treatment was completed without a planned treatment break (Figure 1). The technical aspects of CyberKnife radiosurgical system for cranial tumors have been described in detail $[17,18]$. The treatment volume for the radiosurgical boost included the contrastenhancing lesion and the resection cavity as defined by the patient's neurosurgeon plus a $1 \mathrm{~cm}$ margin when clinically indicated (Figure 1A, B). Due to the submillimeter precision of CyberKnife treatment, no additional margin was added to correct for set-up inaccuracy. The treating neurosurgeon and radiation oncologist in consultation determined the prescription isodose line (Figure 1C). Twelve circular collimator ranging in diameter form 5 to $60 \mathrm{~mm}$ are available with the CyberKnife radiosurgical

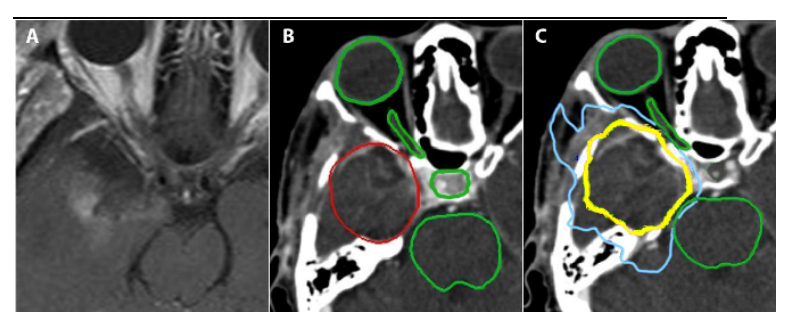

Figure 1 (A) Axial T1-weighted post contrast MRI illustrating a right-sided temporal lobe high-grade glioma resection cavity bordering the right optic nerve, optic chiasm and brainstem. (B) Planning Axial CT image. The radiosurgical planning treatment volume is contoured in red and critical structures are contoured in green. (C) Planning Axial CT illustrating the prescription isodose line in yellow and the $50 \%$ isodose line in blue. system. An inverse planning method with non-isocenteric technique was used. The treating physician and physicist input the specific treatment criteria, limiting the maximum dose to critical structures (Figure $1 \mathrm{C}$ ). The planning software calculated the optimal solution for treatment. The DVH of each plan was evaluated until an acceptable plan was generated. Strict adherence to critical normal structure dose constraints was maintained (Table 1).

\section{CyberKnife Treatment Planning Parameters Treatment Volume}

Treatment volume was defined as the volume contoured on the planning $\mathrm{CT}$ scan by the treating neurosurgeon plus a $1 \mathrm{~cm}$ margin when clinically indicated. In this study, there was no limit set on the treatable target volumes.

\section{Homogeneity Index}

The homogeneity index (HI) describes the uniformity of dose within a treated target volume, and is directly calculated from the prescription isodose line chosen to cover the margin of the tumor:

\section{$\mathrm{HI}=$ Maximum dose/prescription dose}

\section{New Conformity Index}

The new conformity index (NCI) as formulated by Paddick [21], and modified by Nakamura [22] describes the degree to which the prescribed isodose volume conforms to the shape and size of the target volume. It also takes into account avoidance of surrounding normal tissue.

\section{Percent Target Coverage}

PTC $=$ The percentage of the target volume covered by the prescription isodose line. 


\section{CyberKnife Treatment Delivery}

Image-guided radiosurgery was employed to eliminate the need for stereotactic frame fixation. Using computed tomography planning, target volume locations were related to cranial landmarks. With the assumption that the target position is fixed within the cranium, cranial tracking allows for anatomy based tracking relatively independent of patient's daily setup. Position verification was validated every third beam during treatment using paired, orthogonal, $x$-ray images $[23,24]$.

\section{Chemotherapy}

Patients received concurrent and/or adjuvant chemotherapy at the discretion of their medical oncologist. Typically, patients were administered Temozolomide with concurrent radiation at a dose of $75 \mathrm{mg} / \mathrm{m} 2 / \mathrm{d}$, given $7 \mathrm{~d} /$ wk from the first day of conventional irradiation until the last day of CyberKnife treatment. After a 4-week break, patients generally received 6 cycles or more of adjuvant Temozolomide on a 5 -day schedule of 150 to $200 \mathrm{mg}$ per square meter every 28 days.

\section{Clinical Assessment and Follow-up}

Clinical evaluation and MRI imaging were performed at 3-6 month intervals following CyberKnife treatment for 5 years. Evaluation frequency beyond 5 years was determined by the medical oncologist. Throughout the followup period, a multidisciplinary team of neurosurgeons, radiation oncologists, medical oncologist and radiologists reviewed outcomes at a weekly central nervous system tumor board. Toxicity was scored according to the National Cancer Institute Common Terminology Criteria for Adverse Events, Version 3.0 [25]

\section{Statistical Analysis}

The follow-up duration was defined as the time from the date of surgery to the last date of follow-up for surviving patients or to the date of death. Actuarial survival and local control was calculated using the Kaplan-Meier method.

\section{Results}

\section{Patient and Tumor Characteristics}

Twenty four consecutive eligible patients were treated over a seven year period extending from January 2002 to January 2009 (Table 2) and were followed for a minimum of 12 months or until death. The mean age of the group was 52 years (range, 27-72). Tumors were evenly distributed between anaplastic glioma (WHO III) and glioblastoma multiformi (WHO IV). Ninety-two percent of the tumors involved the temporal and/or frontal lobes.

\section{Treatment Characteristics}

Thirteen tumors were completely resected; eleven were subtotaly resected. All patients received conventional radiation therapy following tumor resection, with a median dose of 50 Gy (range: 40 - 50.4 Gy). Upon completion of conventional treatment, an additional dose of 10 Gy was delivered in five successive 2 Gy daily fractions utilizing the CyberKnife image-guided radiosurgical system. Treatment plans were composed of hundreds of pencil beams shaped using a single circular collimator to generate highly conformal plans (mean new conformity index of 1.62, Table 3). Selected plans were inhomogeneous by design (mean homogeneity index of 1.38 , Table 3) to minimize dose to adjacent critical structures. Radiation was delivered to a mean prescription isodose line of $73 \%$ (Table 3) in 5 approximately 1 hour long treatments. On average, 173 beams were employed to treat the mean prescription volume of $174 \mathrm{cc}$ with a mean percent target coverage of $94 \%$. An average of 58 verification images were taken during each treatment to account for intrafraction patient motion. Twenty-one patients received concurrent and/or adjuvant Temozolmide. Two patients received adjuvant procarbazine, lomustine, vincristine (PCV) alone and one patient declined chemotherapy.

\section{Outcomes}

The median follow-up was 23 months (range, 13-60 months) for glioblastoma multiforme patients and 63 months (range, 21-85 months) for anaplastic glioma patients (Table 4). No patients were lost to follow-up. Nine of twelve GBM patients (75\%) experienced local progression, seven of which died during the follow-up period. Six of the twelve anaplastic patients (50\%) experienced local progression, four deaths occurred during the clinical follow-up period. The median time to local progression was 16 months for the glioblastoma multiformi group and 33 months for the anaplastic glioma group. The median survival was 18 months for the glioblastoma multiforme group with a two-year survival rate of $37 \%$. The median survival was not reached for the anaplastic glioma group and the 4-year survival rate was $71 \%$ (Figure 2). Of those who died in the glioblastoma multiforme group, 7 (89\%) had local disease progression and of those who died in the anaplastic glioma group $4(100 \%)$ had local disease progression (Figure 2). The median time to death was 18 months for the glioblastoma multiformi group and 36 months for the anaplastic glioma group. There were no severe ( $\geq$ grade 3 ) radiation complications per the National Cancer Institute Common Terminology Criteria for Adverse Events, Version 3.0 with this conservative treatment strategy.

\section{Salvage Therapy}

Ultimately, 16 patients experienced local progression during follow-up (Table 5). Salvage surgery was clinically indicated and pursued in 10 patients, 4 with glioblastoma multiforme and 6 with anaplastic glioma. Each surgery 


\section{Table 3: Treatment Characteristics}

\begin{tabular}{|c|c|}
\hline Characterist & \\
\hline \multicolumn{2}{|c|}{ Homogeneity Index } \\
\hline Min & 1.22 \\
\hline Max & 1.67 \\
\hline Mean & 1.38 \\
\hline Median & 1.43 \\
\hline \multicolumn{2}{|c|}{ New Conformality Index } \\
\hline Min & 1.20 \\
\hline Max & 1.84 \\
\hline Mean & 1.62 \\
\hline Median & 1.54 \\
\hline \multicolumn{2}{|c|}{ Prescription Isodose Line (\%) } \\
\hline Min & 60 \\
\hline Max & 80 \\
\hline Mean & 73 \\
\hline Median & 70 \\
\hline \multicolumn{2}{|c|}{ Treatment Volume (cc) } \\
\hline Min & 13 \\
\hline Max & 550 \\
\hline Mean & 174 \\
\hline Median & 95 \\
\hline \multicolumn{2}{|c|}{ Percent Tumor Coverage } \\
\hline Min & 79 \\
\hline Max & 99 \\
\hline Mean & 94 \\
\hline Median & 96 \\
\hline \multicolumn{2}{|c|}{ Number of Radiation Beams Utilized } \\
\hline Min & 87 \\
\hline Max & 288 \\
\hline Mean & 173 \\
\hline Median & 151 \\
\hline \multicolumn{2}{|c|}{ Number of Verification Images Per Treatment } \\
\hline Min & 29 \\
\hline Max & 96 \\
\hline Mean & 58 \\
\hline Median & 50 \\
\hline
\end{tabular}

Table 4: Group Clinical Outcomes

\begin{tabular}{lcc}
\hline & GBM & Anaplastic \\
\hline Follow-up (Months) & 13 & 21 \\
$\quad$ Min & 60 & 85 \\
Max & 22 & 58 \\
Mean & 23 & 63 \\
Median & & \\
Time to local progression (Months) & 9 & 9 \\
Min & 60 & 48 \\
Max & 20 & 29 \\
Mean & 16 & 33 \\
Median & & \\
Survival (\%) & 37 & 91 \\
2 Year & 19 & 71 \\
4 Year & & \\
Time to Death (Months) & 9 & 21 \\
Min & 60 & 60 \\
Max & 22 & 38 \\
Mean & 18 & 36 \\
Median & 0 & 0 \\
Complications ( $\geq$ Grade 3) & & \\
\hline
\end{tabular}

confirmed recurrent glioma with treatment effect. Necrosis was not observed in the absence of tumor progression. Five patients completed salvage chemotherapy, 3 from the glioblastoma multiformi group and 2 from the anaplastic glioma group. A single glioblastoma multiforme patient survived 10 weeks following salvage CyberKnife radiosurgery.

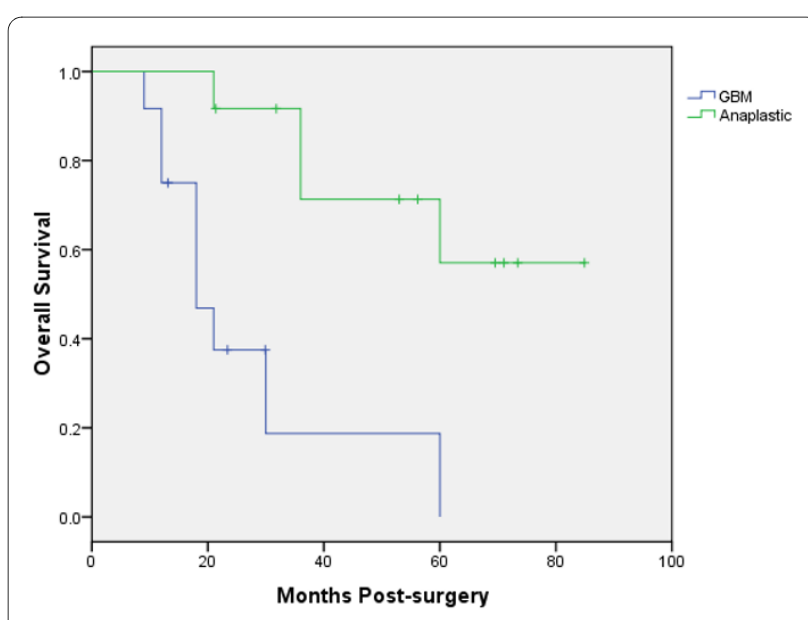

Figure 2 Kaplan-Meier plot of overall survival 
Table 5: Individual Clinical Outcomes

\begin{tabular}{|c|c|c|c|c|c|c|c|}
\hline Patient & $\begin{array}{l}\text { Time to Progression } \\
\text { (months) }\end{array}$ & $\begin{array}{l}\text { Vital } \\
\text { Status }\end{array}$ & $\begin{array}{l}\text { Time to Death } \\
\text { (months) }\end{array}$ & $\begin{array}{l}\text { Clinical Follow-up } \\
\text { (months) }\end{array}$ & $\begin{array}{c}\text { Salvage } \\
\text { Radiation }\end{array}$ & $\begin{array}{c}\text { Salvage } \\
\text { Chemotherapy }\end{array}$ & $\begin{array}{l}\text { Salvage } \\
\text { Surgery }\end{array}$ \\
\hline 1 & 18 & Dead & 30 & $\mathrm{n} / \mathrm{a}$ & No & No & No \\
\hline 2 & 18 & Dead & 21 & $\mathrm{n} / \mathrm{a}$ & No & No & Yes \\
\hline 3 & $\mathrm{n} / \mathrm{a}$ & Alive & $\mathrm{n} / \mathrm{a}$ & 73 & No & No & No \\
\hline 4 & 36 & Dead & 36 & $\mathrm{n} / \mathrm{a}$ & No & No & Yes \\
\hline 5 & $\mathrm{n} / \mathrm{a}$ & Alive & $\mathrm{n} / \mathrm{a}$ & 70 & No & No & No \\
\hline 6 & $\mathrm{n} / \mathrm{a}$ & Alive & $\mathrm{n} / \mathrm{a}$ & 85 & No & No & No \\
\hline 7 & $\mathrm{n} / \mathrm{a}$ & Alive & $\mathrm{n} / \mathrm{a}$ & 71 & No & No & No \\
\hline 8 & 15 & Dead & 21 & $\mathrm{n} / \mathrm{a}$ & No & No & Yes \\
\hline 9 & 9 & Dead & 12 & $\mathrm{n} / \mathrm{a}$ & Yes & No & No \\
\hline 10 & 30 & Dead & 36 & $\mathrm{n} / \mathrm{a}$ & No & Yes & Yes \\
\hline 11 & 48 & Dead & 60 & $\mathrm{n} / \mathrm{a}$ & No & No & Yes \\
\hline 12 & 60 & Dead & 60 & $\mathrm{n} / \mathrm{a}$ & No & Yes & No \\
\hline 13 & 36 & Alive & $\mathrm{n} / \mathrm{a}$ & 56 & No & No & Yes \\
\hline 14 & 9 & Dead & 12 & $\mathrm{n} / \mathrm{a}$ & No & Yes & Yes \\
\hline 15 & $\mathrm{n} / \mathrm{a}$ & Alive & $\mathrm{n} / \mathrm{a}$ & 53 & No & No & No \\
\hline 16 & 9 & Dead & 18 & $\mathrm{n} / \mathrm{a}$ & No & No & Yes \\
\hline 17 & 16 & Dead & 18 & $\mathrm{n} / \mathrm{a}$ & No & No & No \\
\hline 18 & 30 & Alive & $\mathrm{n} / \mathrm{a}$ & 30 & No & No & Yes \\
\hline 19 & $\mathrm{n} / \mathrm{a}$ & Alive & $\mathrm{n} / \mathrm{a}$ & 32 & No & No & No \\
\hline 20 & 12 & Dead & 18 & $\mathrm{n} / \mathrm{a}$ & No & No & No \\
\hline 21 & 9 & Alive & $\mathrm{n} / \mathrm{a}$ & 21 & No & Yes & Yes \\
\hline 22 & 16 & Alive & $\mathrm{n} / \mathrm{a}$ & 23 & No & Yes & No \\
\hline 23 & $\mathrm{n} / \mathrm{a}$ & Dead & 9 & $\mathrm{n} / \mathrm{a}$ & No & No & No \\
\hline 24 & $\mathrm{n} / \mathrm{a}$ & Alive & $\mathrm{n} / \mathrm{a}$ & 13 & No & No & No \\
\hline
\end{tabular}




\section{Discussion}

High grade gliomas adjacent to critical structures are difficult to treat with conventional radiation therapy technique alone [15]. When irradiating such tumors strict adherence to critical normal structure dose constraints may spare tumors full dose irradiation, potentially resulting in premature local failure and death. Conversely, delivering high doses of radiation immediately adjacent to critical structures without strict limitation increases the risk of late radiation induced complications [9]. Temozolomide-related improvements in high-grade glioma survival have amplified this risk. The number of patients with glioblastoma multiforme surviving past two years is increasing (> 20\%) [4] and more than half of patients with anaplastic gliomas are expected to live longer than 4 years. [5,6] These statistics justify current attempts to limit late radiation morbidity. While 3D-conformal radiation therapy [26] and IMRT [27] treatment plans appear to adequately treat the target volume and spare adjacent critical structure, documented set-up inaccuracies and uncorrected intrafraction patient motion increase the risk of potentially costly radiation misadministration.

In this study, we utilized the highly conformal and accurate fractionated CyberKnife radiotherapy to enhance conventional radiotherapy and investigated the safety and efficacy of this technique. The CyberKnife radiosurgical system has several advantages over conventional radiation delivery systems. Since hundreds of nonisocentric treatment beams are available, the CyberKnife is capable of delivering a highly conformal treatment $[17,18]$. Cranial tracking, using skeletal anatomy to position the radiation beam, is as precise as frame-based approaches (accuracy $<1 \mathrm{~mm}$ ) [28-31]. Furthermore, by rendering invasive head frames unnecessary, the CyberKnife approach facilitates fractionate treatment while maintaining radiosurgical accuracy.

This is the first study to evaluates CyberKnife enhanced conventionally fractionated radiation therapy and chemotherapy for high-grade gliomas. Twenty-four patients were treated with encouraging 2 year and 4 year overall survival rates of $37 \%$ and $71 \%$ for the glioblastoma multiforme and anaplastic glioma cohorts, respectively. There were no severe late toxicities attributed to this technique using conventional total radiation doses of approximately 60 Gy. Our results demonstrate the feasibility, tolerability and efficacy of delivering CyberKnife enhanced conventionally fractionated radiation therapy and chemotherapy. Unfortunately, local progression remains the predominant pattern of failure for these patients despite optimal radiation treatment and chemotherapy (Figure 3) as confirmed by our salvage surgery analysis (Table 5). Nonetheless, image-guided radiation remains a useful

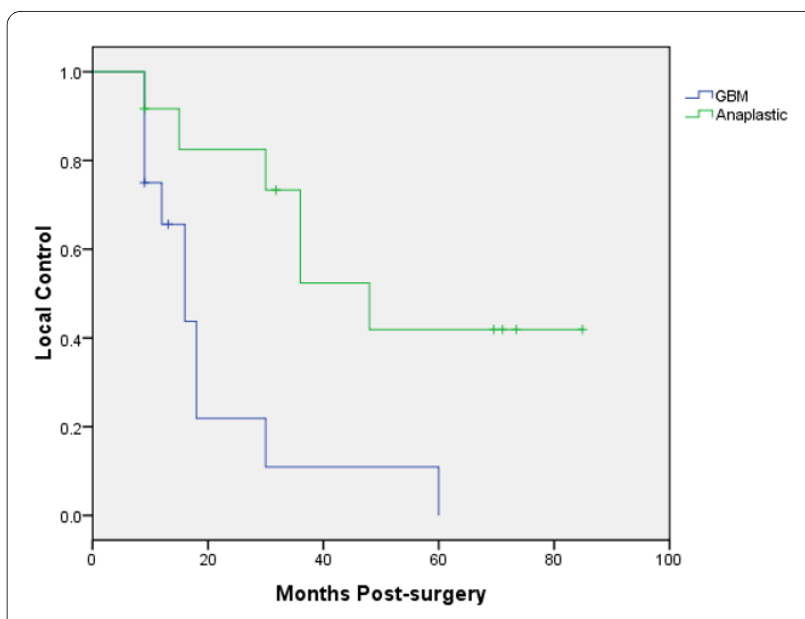

Figure 3 Kaplan-Meier plot of local control

tool to optimize available treatment for patients with tumors in close proximity to critical structures.

\section{Competing interests}

$\mathrm{BC}$ is an Accuray clinical consultant.

\section{Authors' contributions}

EO participated in data collection, data analysis and manuscript preparation. $\mathrm{BC}$ participated in drafting the manuscript, treatment planning, data collection and data analysis. KE participated in data collection, data analysis and manuscript revision. XY participated in treatment planning, data collection and data analysis. SL participated in treatment planning, data collection and data analysis. SS created tables and figures and participated in data analysis and manuscript revision. $\mathrm{HH}$ participated in data collection, data analysis and manuscript revision. JK participated in data collection, data analysis and manuscript revision. HP created tables and figures and participated in data analysis and manuscript revision. AE participated in data collection, data analysis and manuscript revision. CK participated in treatment planning, data analysis and manuscript revision. KM participated in treatment planning, data analysis and manuscript revision. DS participated in data analysis and manuscript revision. WJ participated in treatment planning, data analysis and manuscript revision. SC participated in drafting the manuscript, treatment planning, data collection and data analysis. All authors have read and approved the final manuscript.

\section{Author Details}

'Department of Radiation Oncology, Georgetown University Hospital, Washington, DC, USA, ${ }^{2}$ Department of Neurosurgery, Georgetown University Hospital, Washington, DC, USA and 'Department of Hematology and Oncology, Georgetown University Hospital, Washington, DC, USA

Received: 31 March 2010 Accepted: 9 June 2010

Published: 9 June 2010

\section{References}

1. Jemal A, Siegel R, Ward E, Hao Y, Xu J, Thun MJ: Cancer statistics, 2009. CA Cancer J Clin 2009, 59(4):225-49.

2. Wallner KE, Galicich JH, Krol G, Arbit E, Malkin MG: Patterns of failure following treatment for glioblastoma multiforme and anaplastic astrocytoma. Int J Radiat Oncol Biol Phys 1989, 16(6):1405-9.

3. Stupp R, Hegi ME, Gilbert MR, Chakravarti A: Chemoradiotherapy in malignant glioma: standard of care and future directions. J Clin Oncol 2007, 25(26):4127-36.

4. Stupp R, Hegi ME, Mason WP, van den Bent MJ, Taphoorn MJ, Janzer RC, Ludwin SK, Allgeier A, Fisher B, Belanger K, Hau P, Brandes AA, Gijtenbeek J, Marosi C, Vecht CJ, Mokhtari K, Wesseling P, Villa S, Eisenhauer E, Gorlia T, Weller M, Lacombe D, Cairncross JG, Mirimanoff RO, European Organisation for Research and Treatment of Cancer Brain Tumour and Radiation Oncology Groups; National Cancer Institute of Canada Clinical 
Trials Group: Effects of radiotherapy with concomitant and adjuvant temozolomide versus radiotherapy alone on survival in glioblastoma in a randomised phase III study: 5 -year analysis of the EORTC-NCIC trial. Lancet Oncol 2009, 10(5):459-66.

5. Prados MD, Seiferheld W, Sandler HM, Buckner JC, Phillips T, Schultz C, Urtasun R, Davis R, Gutin P, Cascino TL, Greenberg HS, Curran WJ Jr: Phase III randomized study of radiotherapy plus procarbazine, lomustine, and vincristine with or without BUdR for treatment of anaplastic astrocytoma: final report of RTOG 9404. Int J Radiat Oncol Biol Phys 2004, 58(4):1147-52.

6. van den Bent MJ, Carpentier AF, Brandes AA, Sanson M, Taphoorn MJ, Bernsen HJ, Frenay M, Tijssen CC, Grisold W, Sipos L, Haaxma-Reiche H, Kros JM, van Kouwenhoven MC, Vecht CJ, Allgeier A, Lacombe D, Gorlia T: Adjuvant procarbazine, lomustine, and vincristine improves progression-free survival but not overall survival in newly diagnosed anaplastic oligodendrogliomas and oligoastrocytomas: a randomized European Organisation for Research and Treatment of Cancer phase III trial. J Clin Oncol 2006, 24(18):2715-22.

7. NCCN Clinical Practice Guideline in Oncology: Central Nervous System Cancers. 2009, 3:

8. Salazar OM, Rubin P: The spread of glioblastoma multiforme as a determining factor in the radiation treated volume. Int $\mathrm{J}$ Radiat Oncol Biol Phys 1976, 1(7-8):627-37.

9. Lawrence YR, Li XA, el Naqa I, Hahn CA, Marks LB, Merchant TE, Dicker AP: Radiation Dose-Volume Effects in the Brain. Int J Radiat Oncol Biol Phys 2010, 76(3 Suppl):S20-7.

10. Floyd NS, Woo SY, Teh BS, Prado C, Mai WY, Trask T, Gildenberg PL, Holoye P, Augspurger ME, Carpenter LS, Lu HH, Chiu JK, Grant WH, Butler EB: Hypofractionated intensity-modulated radiotherapy for primary glioblastoma multiforme. Int J Radiat Oncol Biol Phys 2004, 58(3):721-6.

11. Villavicencio AT, Burneikien8 S, Romanelli P, Fariselli L, McNeely L, Lipani JD, Chang SD, Nelson EL, McIntyre M, Broggi G, Adler JR Jr: Survival following stereotactic radiosurgery for newly diagnosed and recurrent glioblastoma multiforme: a multicenter experience. Neurosurg Rev 2009.

12. Souhami L, Seiferheld W, Brachman D, Podgorsak EB, Werner-Wasik M, Lustig R, Schultz CJ, Sause W, Okunieff P, Buckner J, Zamorano L, Mehta MP, Curran WJ Jr: Randomized comparison of stereotactic radiosurgery followed by conventional radiotherapy with carmustine to conventional radiotherapy with carmustine for patients with glioblastoma multiforme: report of Radiation Therapy Oncology Group 93-05 protocol. Int J Radiat Oncol Biol Phys 2004, 60(3):853-60.

13. Cardinale R, Won M, Choucair A, Gillin M, Chakravarti A, Schultz C, Souhami L, Chen A, Pham H, Mehta M: A phase II trial of accelerated radiotherapy using weekly stereotactic conformal boost for supratentorial glioblastoma multiforme: RTOG 0023. Int J Radiat Oncol Biol Phys 2006, 1; 65(5):1422-8.

14. Masi L, Casamassima F, Polli C, Menichelli C, Bonucci I, Cavedon C: Cone beam CT image guidance for intracranial stereotactic treatments: comparison with a frame guided set-up. Int J Radiat Oncol Biol Phys 2008, 71(3):926-33.

15. Noda SE, Lautenschlaeger T, Siedow MR, Patel DR, El-Jawahri A, Suzuki Y, Loeffler JS, Bussiere MR, Chakravarti A: Technological advances in radiation oncology for central nervous system tumors. Semin Radiat Oncol 2009, 19(3):179-86.

16. Walker MD, Strike TA, Sheline GE: An analysis of dose-effect relationship in the radiotherapy of malignant gliomas. Int $J$ Radiat Oncol Biol Phys 1979, 5:1725-31.

17. Collins SP, Coppa ND, Zhang Y, Collins BT, McRae DA, Jean WC: CyberKnife radiosurgery in the treatment of complex skull base tumors: analysis of treatment planning parameters. Radiat Oncol 2006, $1: 46$.

18. Coppa ND, Raper DM, Zhang Y, Collins BT, Harter KW, Gagnon GJ, Collins SP, Jean WC: Treatment of malignant tumors of the skull base with multi-session radiosurgery. J Hematol Oncol 2009, 2:16.

19. Scott CB, Scarantino C, Urtasun R, Movsas B, Jones CU, Simpson JR, Fischbach AJ, Curran WJ Jr: Validation and predictive power of Radiation Therapy Oncology Group (RTOG) recursive partitioning analysis classes for malignant glioma patients: a report using RTOG 90-06. Int J Radiat Oncol Biol Phys 1998, 40(1):51-5.

20. Curran WJ Jr, Scott CB, Horton J, Nelson JS, Weinstein AS, Fischbach AJ Chang $\mathrm{CH}$, Rotman M, Asbell SO, Krisch RE, et al:: Recursive partitioning analysis of prognostic factors in three Radiation Therapy Oncology Group malignant glioma trials. J Natl Cancer Inst 1993, 85(9):704-10.

21. Paddick I: A simple scoring ratio to index the conformity of radiosurgical treatment plans. Technical note. J Neurosurg 2000, 93(Suppl 3):219-22.

22. Nakamura JL, Verhey LJ, Smith V, Petti PL, Lamborn KR, Larson DA, Wara WM, McDermott MW, Sneed PK: Dose conformity of gamma knife radiosurgery and risk factors for complications. Int J Radiat Oncol Biol Phys 2001, 51(5):1313-9.

23. Antypas C, Pantelis E: Performance evaluation of a CyberKnife G4 image-guided robotic stereotactic radiosurgery system. Phys Med Biol 2008, 53(17):4697-718.

24. Murphy MJ, Chang SD, Gibbs IC, Le QT, Hai J, Kim D, Martin DP, Adler JR Jr: Patterns of patient movement during frameless image-guided radiosurgery. Int J Radiat Oncol Biol Phys 2003, 55(5):1400-8.

25. Program CTE: Common Terminology Criteria for Adverse Events, Version 3.0. DCTD N, NIH, DHHS 2006.

26. Chan JL, Lee SW, Fraass BA, Normolle DP, Greenberg HS, Junck LR, Gebarski SS, Sandler HM: Survival and failure patterns of high-grade gliomas after three-dimensional conformal radiotherapy. J Clin Oncol 2002, 20(6):1635-42.

27. Narayana A, Yamada J, Berry S, Shah P, Hunt M, Gutin PH, Leibel SA: Intensity-modulated radiotherapy in high-grade gliomas: clinical and dosimetric results. Int J Radiat Oncol Biol Phys 2006, 64(3):892-7.

28. Adler JR Jr, Murphy MJ, Chang SD, Hancock SL: Image-guided robotic radiosurgery. Neurosurgery 1999, 44:1299-1306. discussion 1306-1297

29. Yu C, Main W, Taylor D, Kuduvalli G, Apuzzo ML, Adler JR Jr: An anthropomorphic phantom study of the accuracy of Cyberknife spinal radiosurgery. Neurosurgery 2004, 55:1138-1149.

30. Chang SD, Gibbs IC, Sakamoto GT, Lee E, Oyelese A, Adler JR Jr: Staged stereotactic irradiation for acoustic neuroma. Neurosurgery 2005, 56:1254-1261. discussion 1261-1253

31. Chang SD, Main W, Martin DP, Gibbs IC, Heilbrun MP: An analysis of the accuracy of the CyberKnife: a robotic frameless stereotactic radiosurgical system. Neurosurgery 2003, 52:140-146. discussion 146147.

doi: $10.1186 / 1756-8722-3-22$

Cite this article as: Oermann et al., CyberKnife ${ }^{\oplus}$ enhanced conventionally fractionated chemoradiation for high grade glioma in close proximity to critical structures Journal of Hematology \& Oncology 2010, 3:22

\section{Submit your next manuscript to BioMed Central and take full advantage of:}

- Convenient online submission

- Thorough peer review

- No space constraints or color figure charges

- Immediate publication on acceptance

- Inclusion in PubMed, CAS, Scopus and Google Scholar

- Research which is freely available for redistribution
C) Biomed Central 